\title{
Abundance Index in Purse Seine Fishery with Searching Time
}

\author{
Tokio Wada ${ }^{* 1}$ and Yoshiharu Matsumiya ${ }^{* 2, * 3}$ \\ (Received July 27, 1989)
}

\begin{abstract}
In the case of purse seine fishery for aggregative pelagic fishes, School Size $\times$ School Density $\times$ Fishing Ground Area was suggested as a basis for the abundance index.

Catch per casting effort and reciprocal of searching time were thought to be proper indices for school size and school density, respectively. The equation for calculating the abundance index was shown and the relation between the variables were theoretically examined when the size of fishing ground changes. The above theory was trially applied to the data from sardine purse seine fishery in the southeast coast of Hokkaido and the validity of equation for variables of abundance index was supported.
\end{abstract}

Catch per unit effort (CPUE) $\times$ area of fishing ground has usually been used as an abundance index for pelagic fishes. ${ }^{1,2}$ In the case of purse seine fishery, however, not only CPUE but also school density (number of fish schools per unit area) should be taken into consideration to get an estimate of abundance index. ${ }^{3}$ )

In this study, theoretical discussion was made concerning: (1) a proper definition of an abundance index in purse seine fishery, and (2) a most reasonable equation when data obtained from purse seine fishery are used to estimate the index. An attempt was made to apply the results obtained through the discussion to a representative sardine fishery by purse seiners in Japan. Although the idea of abundance index is related to both space and time, the discussion was limited to the space, area of the fishing ground alone with a fixed time scale of 10-day period (early, middle and late 10 days of a month).

\section{Theoretical Outline}

\section{Definition of Abundance Index}

The most remarkable characteristic of the purse seine fishery is that a considerable part of the operation is consumed for searching. Once a school was found, the entire fish is to be caught by one net casting. Thus in the case of this fishery, it would be proper to define the abundance index as:
Abundance Index $=$ School Size $\times$ School Density $\times$ Fishing Ground Area (1)

where, the school size in weight and school density (number of schools per unit area) should be variables independent of each other.

\section{Index for School Size}

Another characteristic of the purse seine fishery is that the result is either total success (catch the whole school) or total failure (the whole school escapes the net). It is proper to use catch per casting effort $Y / X(Y$ : catch; $X$ : successful number of net casting, hereafter referred to as the casting effort) as an index for school size. $Y / X$ exactly expresses the average size of schools caught.

\section{Index for School Density}

Discrete aggregations, like fish schools, are usually assumed to be a random distribution. Poisson process can be applied as a school searching operation model. ${ }^{3-a)}$ Under this assumption, $\lambda$, the probability that a school is detected within a unit of time is expressed by the following equation $^{\text {() }}$ :

$$
\lambda=n \frac{W v}{A}
$$

with $n$, the number of fish schools, $A$, the area of fishing ground, $W$, the detection width and $v$, the speed of the searcher. As $W$ and $v$ are assumed to be constant in the same purse seine fishery, the searching time $T$ consumed for detecting a school

*1 Hokkaido National Fisheries Research Institute, Kushiro 085, Japan (和田時夫: 北海道区水研究所).

*2 Ocean Research Institute, University of Tokyo, Tokyo 164, Japan (松宮義睛: 東京大学海洋研究所).

*2 Present address: Faculty of Bioresources, Mie University, Tsu, Mie 514, Japan (三重大学生物 资源学部). 
is inversely proportional to the school density $n / A$. So if $1 / T$ is obtained, it is most suitable as a relative measure for school density because detection of a fish school can be considered to be directly linked to net casting.

If the detection of a fish school is directly linked to net casting, then the casting effort $X$ per unit fishing period is also considered to be a relative index for school density. However, purse seine fishery has some limiting factor of its own, i.e., payload limit of a seiner boat, restriction on catch quantity per day as well as the fact that a larger school size requires the longer time for caught fishes to be loaded onto the boat. Therefore, $X$ per unit fishing period can not be a right measure of index for school density especially when schools are densely distributed.

\section{Equation for Calculating Abundance Index and Area of Unit Fishing Rectangle}

Data on the catch $Y$ and casting effort $X$ are usually arranged by fishing period and fishing rectangle. If we can estimate the searching time $T$ by the unit rectangle, the following equation (3) is provided, instead of equation (1), to calculate the value of abundance index $P^{\prime}{ }_{t}$ for $t$ period:

$$
P^{\prime}{ }_{t}=\sum_{i=1}^{D_{t}}\left\{\left(Y_{t i} / X_{t i}\right)\left(1 / T_{t i}\right)\right\}
$$

where, $D_{t}$ represents the number of rectangles for $t$ period, namely, the area of the fishing ground. However, school searching is performed independently of the unit rectangle, and so it seems that searching time $T$ can be obtained only when the whole fishing ground is taken as an object of the search for each period. In that case, we propose the following equation (4) for the calculation of the abundance index:

$$
P_{t}^{\prime}=\sum_{i=1}^{D_{t}}\left\{\left(Y_{t} / X_{t}\right)\right\}\left(1 / T_{t}\right) .
$$

$Y_{t} / X_{i}$, the average school size in $i$ rectagle, has a higher deviation when the rectagnle is too small and the casting effort is less frequent. When the rectangle is too big, on the other hand, it is possible that sea grounds where no fish schools are distributed at all are mistakenly estimated to be real fishing ground. Therefore, the proper area of a rectangle should be established on the basis of a balance between the above.

\section{Examination of the Case in which Size of Fishing Ground Changes}

The size of fishing ground of aggregative pelagic fish sometimes changes independently of the stock abundance, due to the environmental conditions such as temperature distribution, etc. Either, or both, of the school size and school density may change with such change in the fishing ground area. When stock abundance remains at the same level, an identical abundance index should be obtained by equation (4).

When the size of a fishing ground $D$ changes but stock abundance is constant, school density $1 / T$ should change if school size $Y / X$ is constant, or vice versa. Therefore, the following relations will be observed between these variables:

$$
1 / T \times D=\text { const., or }(Y / X) \times D=\text { const. }
$$

Whether these relations do exist or not can not be confirmed if the information of the fluctuation of stock abundance is not available. It is thought,

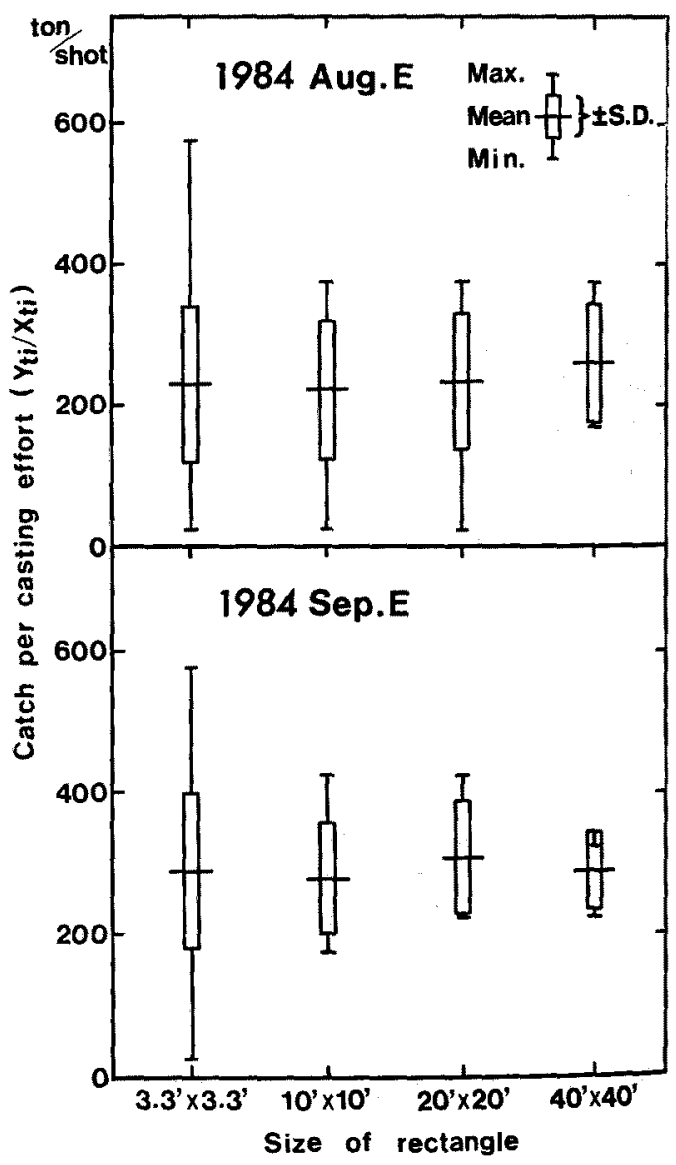

Fig. 1. Range, mean and standard deviation of catch per casting effort $Y_{t i} / X_{t i}$ calculated for four sizes of rectangle. Upper case: early 10day period of August in 1984. Lower case: early 10-day period of September in 1984. 


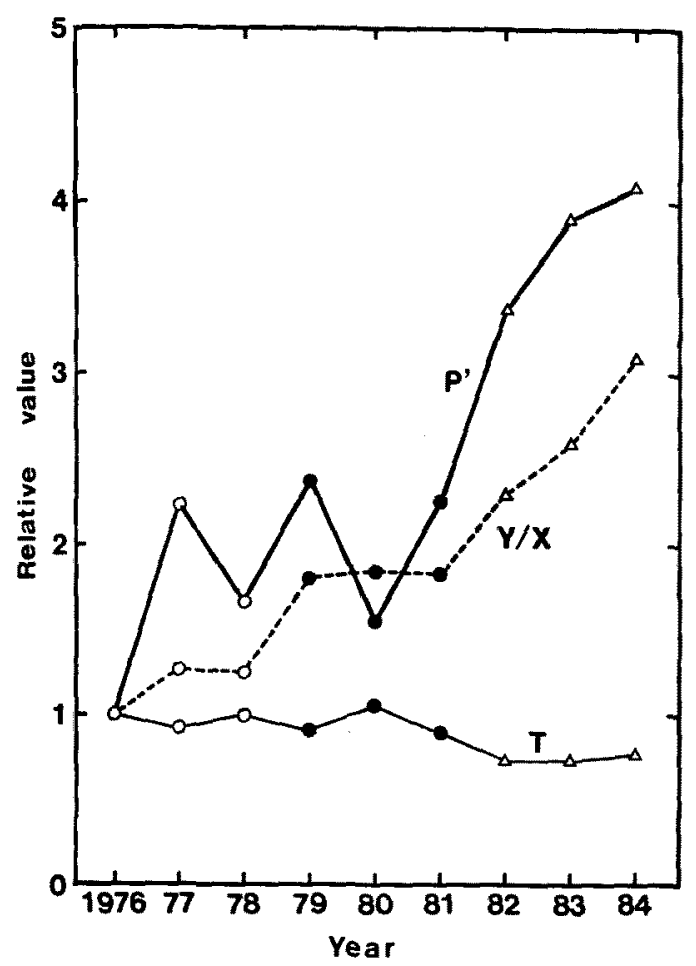

Fig. 2. Yearly variations of abundance index, $P^{\prime}$, catch per casting effort, $Y / X$ and searching time, $T$ for Dohto sardine fishery in 1976-1984. These express in values relative to standard of 1976 (the value of 1.0). See Figs. 3 and 4 for symbols $(O, \bullet, \triangle)$.

however, that the equation (5) may stand if a negative correlation is observed between $D$ and $1 / T$ and between $D$ and $Y / X$, from data obtained during a period when the levels of stock abundance are similar.

\section{Application}

\section{Materials}

To test the theory described above, it was applied to a purse seine fishery data in the waters off the southeast coast of Hokkaido (Dohto region) where a large amount of sardine has been caught since 1976.

Materials used were the fishing operation report called QRY collected from the fishery between 1976-1984, ${ }^{72}$ which contains each purse seiner's hour-to-hour activities (searching, net casting, etc.), catch, location of net casting and so on.

The area of the above fishing operation is about $3.7 \times 10^{4} \mathrm{~km}^{2}$ and the period is from July through October. Twenty-four seiner groups each consisting of a searcher boat, a netting boat and two

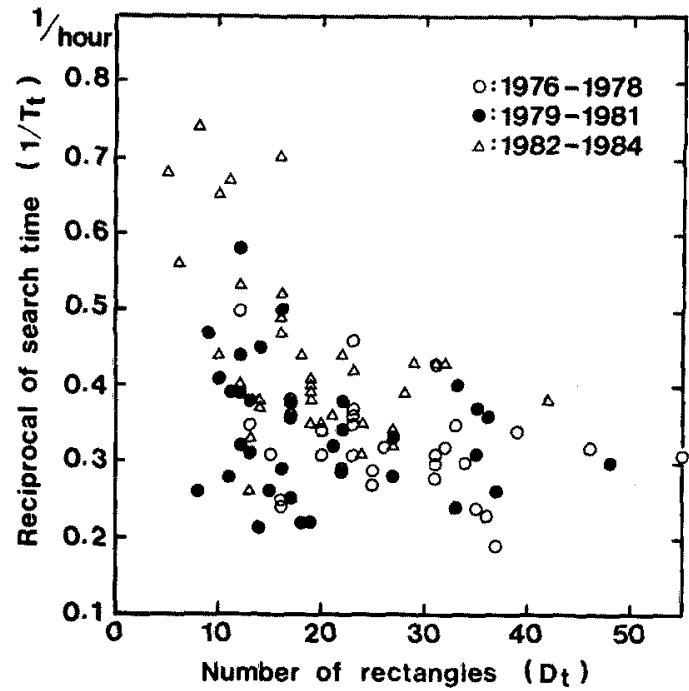

Fig. 3. Relationship observed in three year-groups between number of rectagle, $D_{t}$ and reciprocal of searching time, $1 / T_{t}$. There year-groups are 1976-1978 (O), 1979-1981 (०) and 1982-1984 $(\triangle)$.

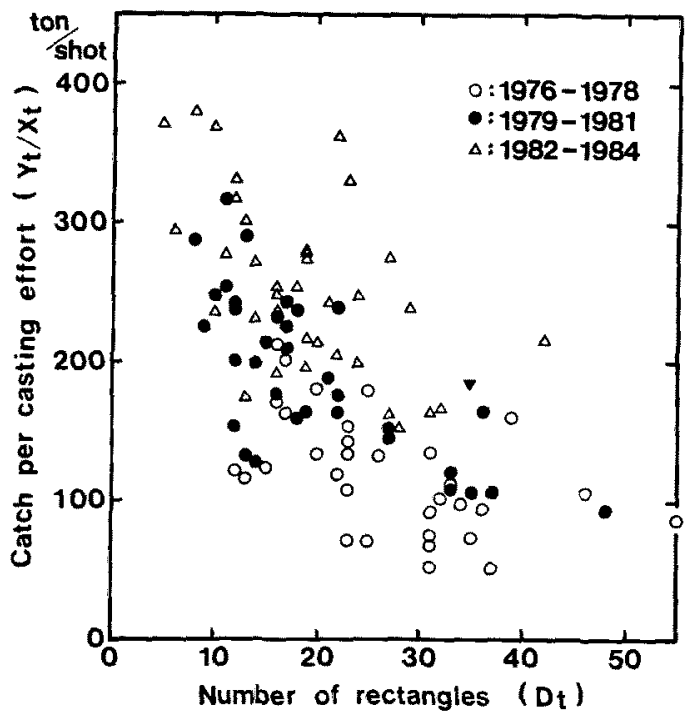

Fig. 4. Relationship observed in three year-groups between number of rectangle, $D_{t}$ and catch per casting effort, $Y_{t} / X_{t}$. Three year-groups are 1976-1978 (O), 1979-1981 (O) and 1982-1984 $(\Delta)$.

cargo boats all of the same type, are operating with their base port at Kushiro. Scanning sonars (echosounder) are used to search fish schools and net casting effort is limited to the daytime.

\section{Results}

Proper size of a fishing rectangle was investigat- 
ed using data during the early 10-day period of August and September in 1984. A unit rectangie was given as the example of four sizes, i.e. $3.3^{\prime} \times$ $3.3^{\prime}, 10^{\prime} \times 10^{\prime}, 20^{\prime} \times 20^{\prime}$ and $40^{\prime} \times 40^{\prime}$, and the range, mean and standard deviation of $Y_{t i} / X_{t b}$ in $t 10$-day period and $i$ rectangle were calculated for each sizes (Fig. 1). The range and standard deviation became smaller but mean stayed at an almost constant level as rectangle size became bigger, and the difference in the range and standard deviation between sizes of $10^{\prime} \times 10^{\prime}$ and $20^{\prime} \times 20^{\prime}$ was not so remarkable. During the high fishing season, grounds are formed in relatively small area. ${ }^{7)}$ Therefore, we decided to adopt $10^{\prime} \times$ $10^{\prime}$ rectangle.

Using the above materials the abundance index $P^{\prime}{ }_{t}$ for each 10-day period can be calculated from equation (4). The sum of $P_{t}^{\prime}$ for a whole fishing season is considered as an index of the total available stock abundance of the year because the migration pattern of sardine to the fishing ground is almost same every year. Wada ${ }^{7)}$ calculated $P^{\prime}$, by adopting $10^{\prime} \times 10^{\prime}$ rectangle and reported that fluctuations of $\boldsymbol{P}_{t}^{\prime}$ in 10-day period as well as year-to-year reflect well the changes in stock $a b$ undance of sardine. We also investigated yearly variations of catch per casting effort $Y / X$ and search time $T$, and showed that $Y / X$ increases while $T$ decreases when $P_{t}^{\prime}$ increases (Fig. 2).

The relations between $D_{t}$ and $1 / T_{t}$, and $D_{t}$ and $Y_{t} / X_{t}$ were obtained for each 10-day period (Figs. 3 and 4 ). In each Figure, the graphic representa- tion is divided, according to stock abundance levels on the basis of Fig. 2, into three yeargroups: 1976-1978, 1979-1981 and 1982-1984. The yearly and seasonal variations of stock abundance for each group are small. In both Figures, it was observed that relations $1 / T_{t}=a / D_{t}$ or $Y_{t} / X_{t}=$ $b / D_{t}(a, b=$ positive constant) were approximately satisfied for each of the three year-groups, and hence the validity of equation (4) was supported.

\section{Acknowledgment}

We would like to thank Dr. M. Mangel of the University of California (U.S.A.) and anonymous referees for reviewing the manuscript and giving us important advice.

\section{References}

1) K. Kurogane: Bull. Tokai Reg. Fish. Res. Lab., 51, 65-80 (1967).

2) Y. Matsumiya and S. Tanaka: Nippon Suisan Gakkaishi, 42, 277-286 (1976).

3) C. W. Clark and M. Mangel: Fish. Bull., 77, 317-337 (1979).

4) J.E. Paloheimo and L. M. Dickie: Rapp. P.V. Réun. Cons. Int. Explor. Mer, 117, 152-163 (1964).

5) J. J. Pella: J. Theoret. Biol., 22, 209-226 (1969).

6) M. Mangel and J. H. Beder: Can. J. Fish. Aquat. Sci., 42, 150-163 (1985).

7) T. Wada: Bull. Hokkaido Reg. Fis. Lab., 52, $1-138$ (1988). 